\title{
VISI DRAMATIK SOEKARNO DALAM DRAMA RAINBOW: POETRI KENTJANA BOELAN
}

\author{
Ikhsan Satria Irianto, Sahrul Nazar, Novesar Jamarun
}

\author{
Minat Studi Pengkajian Seni Teater Program Pascasarjana \\ Institut Seni Indonesia Padangpanjang \\ Jl. Bahder Johan Padangpanjang 27128 Sumatera Barat \\ Email: irianto0307sung@gmail.com
}

\begin{abstract}
Abstrak
Penelitian ini bertujuan untuk mengungkap visi yang melatarbelakangi penulisan dan pementasan drama Rainbow: Poetri Kentjana Boelan. Kasus yang dipertanyakan dalam penelitian ini adalah bagaimana visi dramatik Soekarno dalam drama Rainbow: Poetri Kentjana Boelan? Penelitian ini menggunakan pendekatan kajian sejarah teater dengan metode penelitian kualitatif. Kerangka teoritis yang dipilih untuk menjawab pertanyaan penelitian adalah konsep visi dramatik. Beberapa kesimpulan yang dihasilkan dari penelitian ini adalah melalui drama Rainbow: Poetri Kentjana Boelan, Soekarno memberikan edukasi dan menumbuhkan kesadaran serta menjalin komunikasi dan merancang perjuangan untuk mewujudkan kemerdekaan Indonesia

Kata Kunci: Soekarno, Rainbow: Poetri Kentjana Boelan, Visi Dramatik

\section{Abstract}

This research aims to uncover the vision behind the writing and performance of the drama Rainbow: Poetri Kentjana Boelan. The case in question in this research is how is Soekarno's dramatic vision in the drama Rainbow: Poetri Kentjana Boelan? This study uses a theater history study approach with qualitative research methods. The theoretical framework chosen to answer the research questions is the concept of dramatic vision. Some of the conclusions generated from this research are through the drama Rainbow: Poetri Kentjana Boelan, Soekarno provides education and raises awareness and establishes communication and designs struggles to realize Indonesian independence.
\end{abstract}

Keywords: Soekarno, Rainbow: Poetri Kentjana Boelan, Dramatic Vision

\section{PENDAHULUAN}

Drama merupakan objek fundamental dalam pengkajian tentang teater, hal ini dikarenakan drama merupakan pijakan awal untuk lahirnya peristiwa teater. Proses penciptaan karya teater marupakan proses perwujudan teks kedua dari naskah drama. Leach (2008: 19-20) menambahkan bahwa penulis drama adalah penyedia starting-points untuk kerja teater. Sehingga drama menjadi pokok bahasan yang penting dalam sebuah studi tentang teater.

Drama dalam kajian historis teater merupakan data primer. Banyak hal yang dapat dipelajari dari drama, seperti bagaimana drama itu ditulis, pengaruh zaman, jenis-jenis karakter yang disajikan, bentuk dramatik dan lain sebagainya (Leach, 2008: 19-20). Data yang dihasilkan dari kajian drama tersebut dapat mengungkap visi dramatik pengarang, sejarah akting, penggarapan, pola dramaturgi dan kajian lainnya.

Visi dramatik adalah pandangan filosofis pengarang yang dituliskan dalam bentuk drama. Pandangan tersebut diformulasikan oleh pikiran pribadi pengarang, karena dipengaruhi oleh 
variabel emosional dan intelektual. Visi dramatik dapat diungkapkan dari seniman dalam salah satu dramanya atau dapat diekstrapolasi dari kerja kolektifnya (Strom, 58-59). Berdasarkan pendapat Strom di atas, dapat disimpulkan bahwa visi dramatik bersifat subjektif karena berlandaskan dari perspektif penulis drama.

Setiap penulis drama memiliki visi dramatiknya sendiri, visi dramatik inilah yang membuat setiap drama memiliki orientasi dan kecenderungan yang berbeda. Sopocles menulis drama untuk menjelaskan bahwa manusia tidak mampu melawan takdir dari tuhannya. Beberapa karya Shakespeare ditulis untuk mengkritik dan mengecam keadaan kerajaan Inggris pada saat naskah ditulis. Brect menulis drama sebagai alat perjuangan kelas dan beberapa pengarang lain, seperti Camus dan Sartre menulis drama untuk menyampaikan gagasan filosofisnya.

Dalam proses penyusunan naskah drama, penulis naskah mengalami keterpengaruhan atas kondisi sosial, budaya, sejarah dan semangat zaman yang sedang berlangsung pada saat naskah ditulis. Faktor-faktor inilah yang membuat setiap naskah drama memiliki perbedaan dalam setiap zaman dan setiap wilayah. Sahid (1995: 45) memberikan contoh di Indonesia pada era 40-an dekat dengan masa revolusi, sehingga karyakarya drama yang lahir pada masa itu adalah drama bernuansa revolusi, seperti drama karya Usmar Ismail berjudul Citra dan Api. Pada sisi lain, naskah-naskah yang ditulis pada era 60-an tidak lagi membahas tentang revolusi, karena pada zaman itu Indonesia sedang mengalami masa orde lama dan PKI. Drama pada era ini lebih cenderung pada drama-drama dakwah seperti karya Iqra dan Maulid karya Helmy Nasution.

Ir. Soekarno adalah pahlawan Indonesia yang merupakan tokoh proklamator dan presiden pertama Republik Indonesia. Namun jarang diketahui, bahwa Soekarno adalah seorang seniman yang produktif di masanya. Berbagai karya seni, dari seni rupa hingga seni pertunjukan telah ia ciptakan, salah satunya toneel. Setiap proses produksi pertunjukan toneelnya, Soekarno bertanggung jawab atas semua kerja artistik yang vital. Giebels (2001: 200) menjelaskan bahwa Soekarno berperan sebagai penulis naskah, sutradara, produser, penata artistik hingga manajer pemasaran.

Soekarno telah menulis lebih dari 20 judul drama, sayangnya hanya 16 naskah saja yang berhasil diselamatkan. Beberapa naskah ditulis dan dipentaskan saat ia diasingkan di Ende. Drama-drama karya Soekarno di Ende, antara lain: Dr. Sjaitan, Ero Dinamik, Rahasia Kalimoetoe, Tahoen 1945, Don Louis Pereira, Koetkoetbi, Toberro dan Kummi Torro. Kemudian beberapa naskah lagi ditulis dan dipentaskan saat ia diasingkan di Bengkulu. Beberapa karya drama Soekarno di Bengkulu, antara lain: Rainbow: Poetri Kentjana Boelan, Hantoe Goenoeng Boengkoek, Si Ketjil: Klein' Duimpje dan Chungking Djakarta (Setiyanto, 2006: 2).

Saat dalam masa pengasingan, Soekarno mengisi waktunya dengan melakukan perenungan tentang rencana kemerdekaan dan konsep Negara yang relevan untuk Indonesia. Tidak hanya itu saja, Soekarno juga memanfaatkan waktu pengasingannya untuk memberikan penyadaran dan menumbuhkan rasa nasionalisme kepada masyarakat melalui pertujukan drama (Winet, 2010: 98). 
Berdasarkan penjabaran Winet, dapat disimpulkan bahwa masa pengasingan merupakan priode yang vital dan esensial bagi Soekarno dan juga bagi sejarah Indonesia.

Sebagai interniran, ruang gerak Soekarno dikekang dan dibatasi. Segala macam aktivitasnya mendapatkan pengasawan yang ketat dari pemerintahan Belanda, termasuk aktivitas kreatifnya dalam dunia teater. Sehingga pesan-pesan di dalam setiap dramanya, selalu terselubung dan penuh dengan tanda. Upaya tersebut dilakukan agar makna yang Soekarno sampaikan dapat terbaca oleh masyarakat Indonesia, namun tidak diketahui oleh Belanda, khususnya Politie Inlichtingen Dienst yang bertugas mengawasi segala aktivitas dari Soekarno.

Saat diasingkan di Bengkulu (19381942), proses kreatif Soekarno dilakukan bersama kelompok toneel Monte Carlo. Awalnya kelompok Monte Carlo adalah kelompok musik orkestra, namun setelah kehadiran Soekarno, kelompok ini bertransformasi menjadi kelompok toneel. Soekarno tidak mengalami kesulitan untuk melanjutkan proses kreatifnya di Bengkulu. Agus Setiyanto menjelaskan bahwa Bengkulu lebih potensial untuk mendukung proses kreatif Soekarno. Hal ini dikarenakan Bengkulu telah memiliki fasilitas gedung pertunjukan, yaitu Royal Cinema (Setiyanto, 2006: 25). Salah satu karya Soekarno yang ditulis dan dipentaskan Soekarno di Bengkulu adalah drama Rainbow: Poetri Kenjana Boelan (selanjutnya akan ditulis RPKB).

Drama RPKB adalah drama yang ditulis berlandaskan sejarah Bengkulu. Drama yang ditulis dan dipentaskan di Bengkulu antara tahun 1938-1939 ini menceritakan tentang putri keturunan asli Bengkulu yang diadobsi oleh Comandan Inggris. Setelah dewasa, Rainbow menjadi tokoh yang membawa perdamaian antara Kerajaan Sungai Lemau dan Pemerintahan Inggris. Namun, Rainbow akhirnya tewas oleh orang Hindustan yang memanfaatkan situasi.

\section{STUDI LITERATUR}

Visi dramatik adalah bagian organik yang dapat dijelajahi dalam lakon-lakon. Hadir dalam bentuk simbol yang berfungsi untuk mengungkapkan kedekatan antara visi pengarang dan drama. Situasi dramatik dan percakapan antar tokoh dapat membangun identitas dalam visi dramatik pengarang dan cara penangkapan penonton (Khare: 1998: 461). Strom (1998: 54) menambahkan bahwa visi dramatik adalah kualitas yang muncul dari sebuah karya drama. Kehadiran visi mendahului dan menginspirasi lahirnya karya. Sehingga visi dapat dibaca melalui kualitas yang terkandung di dalam produk artistik. Berdasarkan pendapat dari Khare dan Strom, dapat ditarik kesimpulan bahwa visi dramatik dapat ditelusuri melalui analisis kualitas teks, seperti situasi dramatik dan dialog antar tokoh.

Visi dramatik pengarang juga dapat ditelusuri melalui skema penafsiran tekstual. Tim dan Mendoza (1993: 106) menjelaskan bahwa teks merupakan notasi permanen dari visi dramatik pengarang. Sebuah visi yang harus diwakili oleh pertunjukan. Pertunjukan hanyalah interpretasi parsial atau terjemahan dari esensi teks. Sehingga untuk memahami teater dapat dilakukan melalui analisis teks. Berdasarkan penjabaran di atas, dapat disimpulkan bahwa visi dramatik dapat diungkap 
melalui analisis terhadap teks drama.

Khare

(1998:

461-462)

menambahkan kalau citra dari visi dramatik muncul dari kebutuhan berkomunikasi pengarang drama. Sehingga aspek diluar teks dapat digunakan untuk menghubungkan teks dengan visi dramatik dari pengarang. Meskipun pergerakan plot dan perkembangan karakter dapat mengungkapkan citra dramatik, namun pendekatan identitas dramawan dan eksplorasi diluar teks dapat mengarahkan ke jantung visi mereka. Merujuk dari pendapat Khare, dapat ditarik kesimpulan bahwa selain analisis tekstual, dibutuhkan pula analisis visi dramatik secara kontekstual.

Casado (1996: 556-557) melalui reviewnya atas buku The Dramatic Vision of August Wilson yang ditulis oleh Shannon (1996) menjelaskan bahwa Shannon mengungkap visi dramatik dengan cara melakukan analisis mendalam atas naskah drama, mulai dari dialog hingga karakter tokoh. Kemudian Shannon melakukan penelusuran atas latar belakang penulis naskah. Tahap terakhir adalah mengeksplorasi implikasi politik, sosial dan tema-tema besar lainnya di dalam naskah untuk ditelusuri korelasinya dengan konteks budaya dan sejarah. Berdasarkan kesimpulan dari Casado, tahapan yang dilakukan untuk mengungkap visi dramatik diawali dengan analisis naskah drama dan kemudian analisis dikembangkan pada hubungan tema dan konteks naskah.

\section{METODE PENELITIAN}

Penelitian ini menggunakan metode deskriptif interpretatif dengan pendekatan kualitatif. pengumpulan data yang dipilih adalah studi pustaka, studi dokumen dan studi arsip. Jenis dan sumber data yang dibutuhkan adalah naskah drama RPKB, buku-buku karya Soekarno, arsip wawancara Soekarno bersama Cindy Adams, catatan pribadi Soekarno dan buku serta jurnal pendukung.

Selanjutnya adalah tahap analisis data, yang meliputi penelusuran visi dramatik Soekarno di dalam drama RPKB secara tekstual dan kontekstual. Secara tekstual, visi dramatik Soekarno ditelusuri melalui teks drama RPKB. Sedangkan secara kontekstual, visi dramatik Soekarno ditelusuri melalui analisis keadaan sosial dan kondisi zaman ketika drama RPKB ditulis.

\section{HASIL DAN PEMBAHASAN Visi Dramatik Soekarno Tekstual}

\section{Menumbuhkan \\ Kesadaran Historis}

Soekarno adalah tokoh pergerakan Indonesia pra-kemerdekaan yang memiliki iktikad bahwa bangsa yang besar adalah bangsa yang tidak melupakan sejarah. Sejarah bagi Soekarno adalah sebuah cermin yang dapat menentukan arah pergerakan bagi suatu bangsa untuk maju. Soekarno secara gamblang mengumandangkan pentingnya kesadaran akan sejarah melalui pidatonya yang berisi:

"Djanganlah melihat ke masa depan dengan mata buta! Masa jang lampau adalah berguna sekali untuk mendjadi katja-benggalanja daripada masa jang akan datang! Djangan sekalisekali meninggalkan sedjarah! hai Bangsaku, karena djika engkau meninggalkan sedjarahmu jang sudah, engkau akan berdiri di atas kekosongan dan lantas engkau mendjadi bingung, dan 
perdjoanganmu paling-paling hanya akan berupa amuk belaka!"

Soekarno beranggapan bahwa sejarah adalah bekal dan senjata bagi rakyat Indonesia untuk melepaskan diri dari penjajah dan merebut kemerdekaan. Hal ini dikarenakan sejarah telah membuktikan bahwa bangsa Indonesia adalah bangsa yang kuat. Kerajaankerajaan besar seperti Majapahit, Sriwijaya, Singasari, Kutai, Mataram dan kerajaan besar lainnya adalah bukti bahwa bangsa Indonesia bukanlah bangsa yang lemah.

Agar rakyat Indonesia tidak buta sejarah, Soekarno bahkan bersedia menjadi guru sejarah di sekolah yang didirikan oleh Dr. Deuwes Dekker. Melalui kelas sejarahnya, Soekarno menumbuhkan kesadaran historis kepada sekitar 30 murid. Tujuan Soekarno menjadi guru sejarah adalah agar rakyat Indonesia memiliki basis pengetahuan sejarah sejak kecil. Sehingga saat ia dewasa, anak-anak itu memiliki kepercayaan diri yang besar sebagai bangsa.

Visi

Soekarno

untuk menumbuhkan kesadaran historis juga tergambar di dalam drama RPKB. Drama RPKB mengingatkan kembali rakyat Bengkulu tentang sejarah peperangan yang terjadi pada tahun 1719 di Bengkulu. Pada peperangan tersebut, rakyat Bengkulu yang dipimpin oleh Pengaeran Mangkoe Radja Moeda berhasil mengalahkan Inggris dan mengusirnya dari tanah Bengkulu. Sejarah penting tersebut dapat membakar semangat rakyat Bengkulu untuk kembali bangkit dan memperjuangkan kemerdekaan Indonesia.

Sejak mengajar sejarah di sekolah
Dr. Deuwes Dekker, Soekarno memiliki metode mengajar sejarah yang berbeda. Ia tidak hanya mengajarkan tentang berbagai nama, tempat, tanggal dan tahun saja, tetapi Soekarno lebih menekankan kepada imajinasi. Metode ini dipilih oleh Soekarno agar muridmuridnya tidak hanya mengetahui tentang sejarah, tetapi juga merasakan sendiri peristiwa sejarah tersebut di dalam dirinya. Metode ini juga diterapkan Soekarno di dalam drama RPKB. Melalui pertunjukan drama RPKB, Soekarno tidak hanya ingin mengajarkan tentang sejarah saja, tetapi Soekarno juga mengajak para penonton untuk terlibat secara emosional dengan peristiwa sejarah itu sendiri.

Melalui pamflet pertunjukan drama RPKB, Soekarno mengajak rakyat Indonesia khususnya rakyat Bengkulu untuk mengingat sejarah perjuangan dari Kerajaan Sungai Lemau yang melawan pemerintahan Inggris di Benteng Marlborough pada tahun 1719. Berikut pamflet dari pertunjukan RPKB yang dirancang langsung oleh Soekarno:

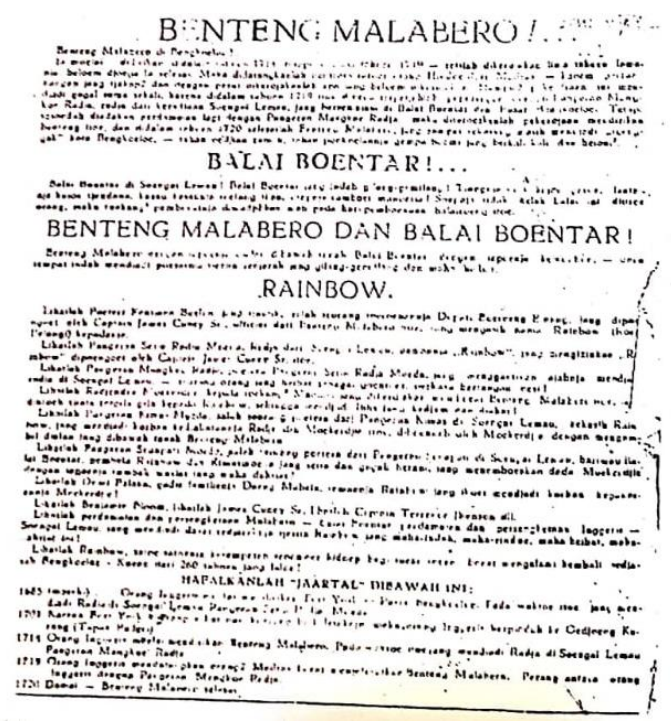

Gambar 1

Pamflet pertunjukan drama Rainbow: Poetri Kentjana Boelan

(Reproduksi dari koleksi Agus Setiyanto, 2020) 


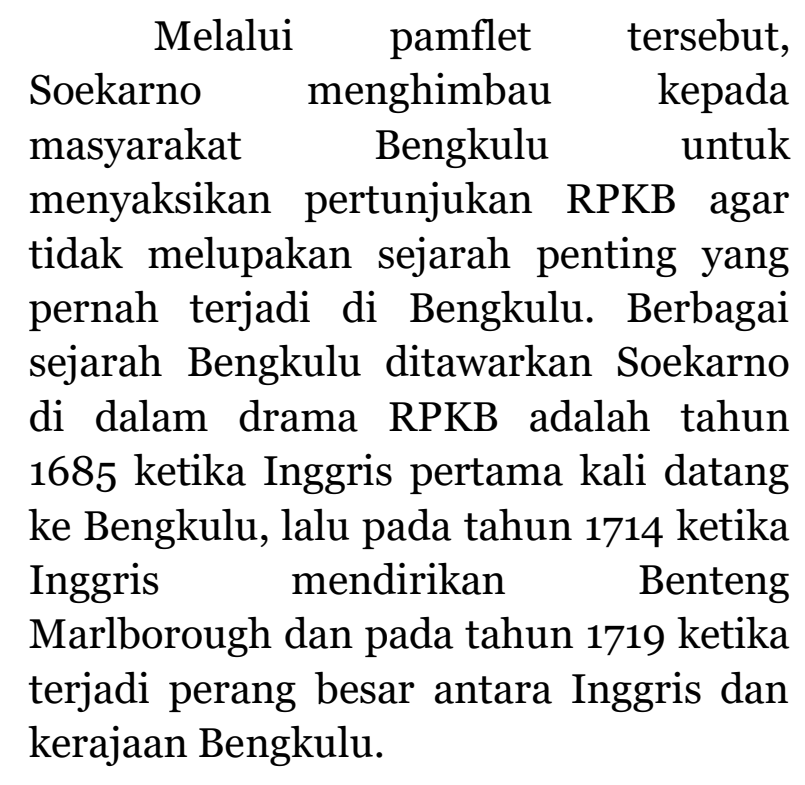

Melalui dialog Pangeran Mangkoe Radja kepada komandan James Cuney, Soekarno ingin menyampaikan bahwa betapa kuat dan beraninya kerajaan Sungai Lemau pada zaman dahulu. Berikut cuplikan dialog antara Pangeran Moekoe Radja dan komandan James Cuney:

153. Pangeran M.R: Tuan Com James Cuney, kau lihat apa ini, ialah satu periuk, kalau tetap dengan pendirian kau serupa inilah nasibnya kau nanti. (lantas periuk dibanting) James Cuney! Mulai hari ini, jam ini, menit ini, detik ini, peperangan saya antara kau bermulai.

\section{Com J.C: Baik!}

155. Pangeran R.M: Kimas Moeda, marilah kita pulang, kita akan mulai peperangan.

Berdasarkan penggalan dialog di atas, tergambar bahwa masyarakat Bengkulu pada zaman dahulu tidak gentar untuk berperang jika ketentramannya terusik. Soekarno berharap setelah menyaksikan drama RPKB, masyarakat Bengkulu sadar karena sejarah telah membuktikan bahwa mereka adalah orang-orang yang kuat dan pemberani. Sehingga tidak ada alasan lagi untuk hidup menghamba dan terjajah.

\section{Menumbuhkan Kesadaran Kebangsaan}

Soekarno berpendapat bahwa Indonesia tidak akan bisa mencapai kemerdekaan jika masih terpecah belah. Salah satu faktor utama yang membuat rakyat Indonesia tidak bersatu adalah setiap rakyat belum memiliki kesadaran kebangsaan atau kesadaraan keIndonesiaan. Ketika setiap rakyat Indonesia tidak memiliki kesadaran kebangsaan maka kepercayaan diri sebagai Bangsa akan runtuh, hal inilah yang dimanfaatkan penjajah untuk menguasai Indonesia.

Melalui tulisannya yang berjudul Nasionalisme, Islamisme dan Marxisme, Soekarno menjelaskan bahwa: "rakjat itu dulunja harus bersama-sama mendjalani satu riwayat dan rakjat itu sekarang harus mempunjai kemauan, keinginan hidup menjadi satu." Melalui sepenggal tulisan tersebut, Soekarno ingin menyampaikan bahwa dahulu bangsa Indonesia pernah bersatu, sehingga tidak ada alasan untuk sekarang menjadi terpecah.

Visi Soekarno untuk menumbuhkan kesadaran kebangsaan juga tergambar di dalam drama RPKB. Melalui drama RPKB, Soekarno menghadirkan peristiwa persatuan rakyat untuk berperang melawan penjajah. Berikut cuplikan dialognya:

134. Pangeran M.R.M: Ya! Tetapi dia belum tahu bagaimana kemarin kakanda, dari kakanda meletakkan jabatan kakanda lebih baik kakanda berperang mati-matian. Bagaimanakah adindaku keduanya?

135. Senomati Moeda: Kakanda, kami berdua bersiap 
membantu kakanda.

136. Pangeran M.R.M:

Bagaimana keadaan dengan kau Daeng Mabella?

137. Daeng Mabela: Daulat Tuanku! Walaupun patik berdarah Bugis tetap patik membantu daulat tuanku!

138. Pangeran M.R.M: Bagaimana kau Pangeran Napal Pandjang?

139. Pangeran N. P: Duli Tuanku! Patik tetap membantu duli Tuanku.

140. Pangeran M.R.M: Nah adindaku keduanya bersiaplah adinda.

Berdasarkan cuplikan dialog di atas, tergambar bahwa seluruh rakyat dan bangsawan Bengkulu bersatu untuk berperang melawan penjajah. Soekarno juga menegaskan bahwa rakyat bisa bersatu dalam satu kekuatan yang besar meskipun berbeda suku, karena sebuah perjuangan tidak memandang perbedaan. Melalui drama RPKB, Soekarno ingin menyadarkan rakyat Indonesia, khususnya rakyat Bengkulu agar dapat bersatu menjadi kekuatan yang besar, tanpa adanya batasanbatasan, ras, suku, bahasa dan agama.

Soekarno juga memberikan edukasi kepada rakyat Bengkulu bahwa kepentingan bangsa harus diprioritaskan di atas kepentingan pribadi. Edukasi tersebut tergambar dari penggalan dialog 142-145:

142. Kimas Moeda: Kakandaku, bukannya adinda takut berperang, bukannya tidak bergembira, hanyalah berperang inilah yang adinda gemari, tetapi adalah satu hal yang adinda pikirkan ialah Rainbow, bagaimanakah kalau terjadi peperangan antara James Cuney dengan kakanda Pangeran
Mangkoe Radja, sedangkan Rainbow masih saudara sepupu kita, masih sedarah dan sedaging dengan kita.

143. Senopati Moeda: Adinda, tahukah oleh adinda yang Com James Cuney sangat cinta pada Rainbow.

144. Kimas Moeda: Betul kakanda, tetapi apakah nanti tidak diperbuatnya Rianbow itu semacam orang tahanan, sebagai orang tawanan?

145. Senopati Moeda: Adinda! Kau jangan takut kakanda akan memperlindungi Rainbow.

Dari penggalan dialog di atas, tergambar bahwa Kimas Moeda harus meninggalkan rasa cinta dan rasa khawatirnya kepada Rainbow, demi berjuang melindungi tanah airnya. Tergambar bahwa Soekarno ingin memberikan edukasi bahwa perjuangan dalam mempertahankan tanah air tidak boleh terganggu oleh perasaan atau kepentingan pribadi.

\section{Menumbuhkan Kesadaran Religius}

Soekarno sadar bahwa bangsa Indonesia adalah bangsa yang religius dan salah satu kekuatan terbesar yang dimiliki oleh rakyat Indonesia adalah kepercayaannya kepada Tuhan yang maha Esa. Indikasi ini tergambar dari banyaknya peperangan antara rakyat Indonesia dan bangsa asing yang mengatasnamakan agama di seluruh wilayah Indonesia, seperti perang Padri (1821-1837), Perang Diponegoro (18251830), Perang Aceh (1987-1904) dan peperangan atas nama agama lainnya. Dari semua peperangan yang mengatasnamakan agama tersebut, tergambar bahwa salah satu kekuatan bangsa Indonesia adalah persatuan umat beragama. 
Melalui drama RPKB, Soekarno mencoba menyadarkan dan menumbuhkan kesadaran religius yang dimiliki rakyat Indonesia, khususnya rakyat Bengkulu. Soekarno menjadikan konflik agama sebagai sumber konflik utama, yaitu perang antara Kerajaan Sungai Lemau dan Pemerintah Inggris. Selengkapnya dapat dilihat dari dialog:

149. Pangeran M.R: Apakah sebetulnya saya akan tuan jatuhkan dari tahta kerajaan? Dengan sebab saya tidak memenuhi kontrak?

150. Com J.C: Benar sekali! 151. Pangeran M.R: Apakah tuan Com tidak tahu, yang bulan ini bulan Ramadhan, bulan yang sangat dimuliakan oleh orang Islam. Dari itu saya tidak bisa memenuhi kewajiban saya, oleh sebab orang-orang Islam ini bulan mesti mengaso.

152. Com J.C: Itu saya tidak bisa pandang, sebab saya sendiri mesti menurut perintah dari Madras.

153. Pangeran M.R: Tuan Com James Cuney, kau lihat apa ini, ialah satu periuk, kalau tetap dengan pendirian kau serupa inilah nasibnya kau nanti. (lantas periuk dibanting) James Cuney! Mulai hari ini, jam ini, menit ini, detik ini, peperangan saya antara kau bermulai.

Dari penggalan dialog di atas, terlihat bahwa Pangeran Mangkoe Radja memutuskan untuk memulai perang dengan Pemerintah Inggris karena Komandan James Cuney tidak bisa mentoleransi aktivitas keagaaman yang sedang dijalankan oleh rakyat Bengkulu. Soekarno menggambarkan secara eksplisit bahwa persoalan agama bukanlah persoalan sepele, rakyat dapat bersatu dan melawan jika kepercayaannya dihina. Melalui drama ini, terlihat jelas bahwa Soekarno ingin menjadikan persoalan agama sebagai salah satu kekuatan pemersatu bangsa Indonesia.

Drama RPKB yang memiliki corak keagamaan ini juga digunakan Soekarno sebagai upaya pendekatan dengan rakyat Bengkulu. Soekarno awalnya dijauhi oleh masyarakat Bengkulu karena pikiran keagamaannya yang dianggap terlalu dinamis. Pemikiran Soekarno tersebut membuat rakyat Bengkulu menjauhi Soekarno karena dianggap memiliki pikiran yang sesat dari ajaran agama Islam. Namun melalui drama RPKB, Soekarno menekankan bahwa musuh sebenarnya adalah para bangsa kolonial. Sesama umat beragama harus bersatu untuk melawan musuh agama.

Meskipun demikian, Soekarno juga menjadikan drama RPKB sebagai media kritik atas cara rakyat Bengkulu yang menganut agama secara konservatif. Soekarno menyampaikan kritiknya melalui dialog 228:

228: Pangeran M.R: Pangeran Napal Pandjang, pergilah kau ke Bengkulu, dan kasih tahu hal ini pada James Cuney. Kemit, ambil perdupaan.

Kemit membawa dupaan serta membakar kemenyan, Com James Cuney datang.

Berdasarkan kutipan dialog di atas, Soekarno menggambarkan bahwa agama yang dianut oleh rakyat Bengkulu adalah agama islam singkretis. Terlihat jelas dari penggunaan dupa dan kemenyan sebagai pelengkap dari prosesi kematian. Soekarno mengkritik cara beragama dari rakyat Bengkulu pada tahun 1939 melalui cara beragama rakyat Bengkulu pada tahun 1719. 


\section{Menumbuhkan Kesadaran Keterjajahan}

Soekarno beranggapan bahwa para penjajah telah mendidik bangsa Indonesia sebagai bangsa yang puas dengan hidup menghamba. Paradigma inilah yang telah diwarisi dari tahun ke tahun, sehingga rakyat Indonesia tidak merasa bahwa mereka sedang terjajah. Tradisi menggantungkan hidup kepada penjajah inilah yang membuat rakyat Indonesia tidak tertarik untuk berjuang merebut kemerdekaan.

Untuk menghancurkan paradigma dan tradisi tersebut, setiap rakyat Indonesia harus menyadari akan keterjajahan mereka. Soekarno menyadarkan rakyat Indonesia dari keterjajahan melalui banyak tulisan yang diterbitkan diberbagai media cetak. Salah satu tulisannya yang begitu frontal adalah tulisan yang berjudul Orang Indonesia Tjucup Nafkahnja Sebenggol Sehari? Soekarno menulis: "Tergambarlah pemerintahan jang di dalam abad kesopanan ini mengatakan rakjatnja tjukup makan sebenggol sehari! Tersadarlah rakjat marhaen jang diperintah pemerintah jang demikian itu!". Dari kutipan tulisan diatas, tergambar bahwa Soekarno secara forntal menyadarkan rakyat Indonesia bahwa hidup terjajah sangatlah menderita.

Melalui drama RPKB, Soekarno juga menyisipi visinya untuk menyadarkan rakyat dari keterjajahannya. Soekarno menyadarkan rakyat melalui dialog James Cuney dan Pangeran Mangkoe Radja, sebagai berikut:

149. Pangeran M.R: Apakah sebetulnya saya akan tuan jatuhkan dari tahta kerajaan?
Dengan sebab saya tidak memenuhi kontrak?

150. Com J.C: Benar sekali!

151. Pangeran M.R: Apakah tuan Com tidak tahu, yang bulan ini bulan Ramadhan, bulan yang sangat dimuliakan oleh orang Islam. Dari itu saya tidak bisa memenuhi kewajiban saya, oleh sebab orang-orang Islam ini bulan mesti mengaso.

152. Com J.C: Itu saya tidak bisa pandang, sebab saya sendiri mesti menurut perintah dari Madras.

Dari cuplikan dialog di atas, Soekarno menggambarkan bagaimana rakyat Bengkulu harus hidup dengan terkekang oleh kontrak yang dibuat Pemerintah Inggris. Rakyat Bengkulu harus tetap bekerja apapun alasannya, meskipun mereka sedang berpuasa. Setelah itu, ketika Pemerintah Inggris merasa rakyat tidak melaksanakan tugasnya, maka itu akan dianggap sebagai pelanggaran kontrak dan termasuk ke kesalahan yang besar.

Drama RPKB juga memperlihatkan bagaimana situasi keterjajahan sistem kerja paksa yang diterapkan penjajah dapat membuat sepasang kekasih tidak dapat menjalin hubungannya dengan tenang dan bahagia. Berikut cuplikan dialognya:

148. Kimas Moeda: Dengar sumpah adinda, adinda bersumpah, disaksi dengan bumi dan angkasa, disaksi dengan lautan Hindia, disaksi dengan pulau Perca Selatan, sekiranya jadi peperangan ini adinda tetap memperlindungi Rainbow, walaupun serangan darimana juga pun. Kalau dalam pertempuran ini adinda tewas jiwanya adinda kakandalah jadi melindungi dan menjaga Rainbow. 
Dari penggalan dialog di atas tergambar bahwa peperangan antara Pemerintah Inggris dan Kerajaan Sungai Lemau membuat Kimas Moeda dan Rainbow tidak dapat menjalin hubungan dengan tenang dan bahagia, sebaliknya selalu ada ketakutan untuk berpisah karena Kimas Moeda harus mempertaruhkan nyawa dalam peperangan.

Soekarno ingin menggambarkan betapa sengsaranya jika hidup dibawah aturan penjajah. Melalui drama RPKB, Soekarno ingin memberikan penyadaran bahwa praktek kolonialisme belumlah selesai. Rakyat Bengkulu haruslah sadar, bahwa apa yang dialami oleh tokohtokoh di dalam drama RPKB, masih dan akan terus mereka alami. Soekarno berharap setelah menonton drama RPKB, rakyat Bengkulu sadar bahwa mereka sedang terjajah dan harus bangkit melawan.

\section{Pengalihan Isu Secara Tematik}

Proses pengalihan isu yang dilakukan Soekarno dalam drama RPKB tergambar dari pemilihan tema mayor dan tema minornya. Soekarno mengusung tema "balas dendam" sebagai tema mayor atau fokus utama dari cerita. Sehingga polisi kolonial Belanda tidak menganggap pertunjukan drama RPKB berbahaya dan bukan sebagai media Soekarno berkomunikasi dengan rakyat. Padahal Soekarno menyisipkan visi perjuangannya melalui tema-tema minor di dalam drama RPKB, yaitu "perang melawan kolonialisme".

Pengalihan isu di dalam drama RPKB yang pertama adalah perombakan sejarah. Drama RPKB berangkat dari sejarah perang antara rakyat Bengkulu dan Pemerintah Inggris di Bengkulu pada tahun 1719. Perang tersebut merupakan salah satu peristiwa yang besar bagi rakyat Bengkulu, karena peperangan tersebut dimenangkan oleh rakyat Bengkulu. Ahmad Ramadoni mengatakan bahwa tokoh yang menjadi pemimpin penyerbuan Benteng Marlborough pada tahun 1719 adalah Pangeran Mangkuradja dari Sungai Lemau, Pengeran Intan Ali dari Selebar, Pangeran Sungai Itam dan juga Syed Ibrahim yang merupakan salah satu ulama besar Bengkulu.

Berdasarkan data sejarah, perang 1719 dimenangkan oleh rakyat Bengkulu sekaligus berhasil mengusir Inggris untuk kembali ke Madras. Namun, Soekarno merubah alur ceritanya di dalam drama RPKB. Soekarno membuat peperangan yang terjadi pada tahun 1719 diakhiri dengan perdamaian. Perombakan sejarah tersebut dilakukan oleh Soekarno secara sengaja, bukan karena Soekarno tidak memahami secara detail dari sejarah perang pada tahun 1719 di Bengkulu. Namun, perombakan tersebut dilakukan agar drama RPKB tidak menyudutkan pihak Inggris sebagai representasi Bangsa Barat.

Pengalihan isu yang kedua adalah Soekarno menghadirkan tokoh-tokoh dari Pemerintah Inggris yang baik hati. Gambaran tokoh Inggris yang memiliki karakter yang baik hati dapat di lihat dari penggalan dialog 34-38:

34. Captain J.C: Kasihan sekali, sudah menjadi semang piyatu, begini kecil, oh Magretha dan saya punya anak namanya Marie.

35. Pangeran: Tuan Captain! Apakah itu Magretha dan Marie!

36. Captain J.C: Ya Pangeran, saya ingat, saya punya istri namanya Magretha dan saya punya anak namanya Marie, yang 
telah lama meninggal dunia, rupanya tak ubahnya dengan ini anak!

37. Pangeran S.R.M: O, jadi begitu!

38. Captain J.C: Ya Tuan Pangetan, jika tidak berkeberatan bolehkah tuan memberi anak ini kepada saya?

Dari cuplikan dialog di atas, terlihat Kapten James Cuney berempati kepada anak yang telah ditinggalkan ibunya saat masih kecil. Tidak hanya itu saja, James Cuney juga bersedia mengadobsi anak tersebut untuk bisa ia rawat dan besarkan. Karakter tokoh James Cuney yang baik hati dipertegas kembali pada penggalan dialog 179-182:

179. Com J.C: Tuan Pangeran silahkan duduk!

180. Pangeran M.R: Terima kasih, tuan Com!

181. Rainbow: Hallo daddy. Apakah daddy kehilangan Rainbow.

182. Com J.C: Walaupun beberapa hari saja, tetapi perasaan daddy lebih dari satu tahun.

Dari cuplikan dialog di atas, tergambar bahwa James Cuney rela mengakhiri perang karena rasa cinta kepada anaknya. Menghadirkan perwakilan dari bangsa Barat yang baik hati membuat proses kreatif Soekarno tidak dicurigai. Bahkan, pemerintah Belanda akan senang saat menyaksikannya.

Pengalihan isu yang ketiga adalah menghadirkan hubungan rakyat Bengkulu dan Pemerintah Inggris yang damai dan harmonis. Padahal, berdasarkan data sejarah hubungan antara kerajaan di Bengkulu dengan pihak pemerintah Inggris memiliki ketegangan sosial yang berkepanjangan.
Puncak dari ketegangan sosial tersebut adalah terbunuhnya Pangeran Nata Diradja oleh Inggris di Fort York pada tanggal 4 November 1710.

Namun, Soekarno di dalam drama RPKB meghadirkan hubungan Kerajaan Bengkulu dan Pemerintah Inggris baikbaik saja. Hubungan antara kedua penguasa di Bengkulu dapat dilihat dari penggalan dialog:

41. Com B.B: Tuan Pangeran, Baiklah tuan, kasihlah sama Captain James Cuney jangan lagi meninggalkan yang kita telah bersahabat baik dari tahun 1605 , jadi ini pemberian kita pandang sebagai tanda mata persahabatan kita .

Kemudian dipertegas kembali pada dialog 89-90:

89. Rainbow: Tetapi daddy sebetulnya kami tadi diantar oleh dua orang pemuda, yaitu Pangeran Kimas Moeda anaknya Pangeran Kimas, yang satu lagi Pangeran Senopati Moeda anaknya Pangeran Senopati, suruhlah kedua pemuda itu masuk.

90. Com J.C: Ya, saya sama bapaknya Pangeran Kimas dan Senopati, saya kenal betul, tetapi sama anak-anaknya belum lagi. Suruh saja dia masuk.

Dari dua penggalan dialog di atas, tergambar bahwa tidak ada sedikit pun ketegangan sosial antara pihak penguasa Bengkulu dan Pemerintah Inggris. Soekarno sengaja merombak sejarah dan membuat hubungan Inggris dan Bengkulu menjadi harmonis agar drama RPKB tidak dianggap menyudutkan bangsa Barat dan kecurigaan pemerintah Belanda terhadap Soekarno dapat diminimalisirkan. 
Pengalihan isu yang ke empat adalah perselisihan antara orang Bengkulu dan orang dari Madras. Pengalihan isu ini menempatkan posisi Inggris tidak terlibat di dalam masalah antara kedua belah pihak. Soekarno memfokuskan konflik drama RPKB antara tokoh Senopati Moeda dari Kerajaan Sungai Lemau Bengkulu dan R. Moekerdji dari Madras, sehingga persoalan yang diangkat dalam drama RPKB terlihat bukan masalah antikolonialisme, tetapi masalah cinta dan pembalasan dendam.

Pengalihan isu ini dapat membuat pemerintah Belanda menyangka drama RPKB hanya berkisah tentang cinta yang berakhir tragis saja, tanpa ada tendensi apa-apa dari Soekarno. Posisi pemerintah Inggris yang tidak terlibat dari konfik utama membuat drama RPKB terlihat tidak menyudutkan bangsa Barat sebagai pokok permasalahan. Meskipun pada babak 3 dan 4, Soekarno menghadirkan peperangan antara Kerajaan Sungai Lemau dan Pemerintah Inggris, tetapi persitiwa tersebut tertutupi oleh konflik utama, yaitu pembalasan dendam.

Berhasilnya drama RPKB dipentaskan pada tahun 1939 dan tidak dihentikannya proses kreatif Soekarno dalam berkesenian saat di Bengkulu, membuktikan bahwa tema mayor di dalam drama RPKB berhasil mengalihkan tema-tema minor yang bersifat propaganda. Sehingga Soekarno tetap dapat berkomunikasi dengan rakyat Bengkulu tanpa dicurigai oleh polisi kolonial. Proses kreatif ini merupakan upaya perlawanan Soekarno secara terselubung melalui media seni teater.

\section{Mempertegas Peran Perempuan}

Sejak pertama menginjakkan kaki di Bengkulu, Soekarno langsung mengkritik sistem sosial masyarakat Bengkulu yang memosisikan perempuan sebagai kaum inferior. Soekarno mengkritik penggunaan tabir bagi perempuan dalam sebuah rapat, ia beranggapan bahwa tabir adalah lambang perbudakan. Persoalan tabir untuk kaum perempuan tersebut ditentang keras oleh Soekarno, bahkan ia memutuskan untuk meninggalkan rapat umum Muhammadiyah sebagai bentuk protesnya.

Melalui tulisan yang berjudul Tabir Adalah Lambang Perbudakan, Soekarno menegaskan bahwa Islam tidak mewajibkan adanya tabir, karena Islam tidak mau memperbudak perempuan. Sebaliknya, Islam mau mengangkat derajat perempuan (Soekarno, 1964: 349). Namun, pikiran Soekarno tentang Islam yang dianggap dinamis ini membuat masyarakat Bengkulu, terutama tokoh agama mulai membuat jarak dari Soekarno.

Melalui drama RPKB, Soekarno menegaskan kembali peran perempuan di dalam sistem sosial masyarakat. Tokoh Rainbow adalah corong Soekarno menyampaikan visi feminisnya. Soekarno menggambarkan tokoh Rainbow sebagai tokoh perempuan yang kuat dan pemberani. Karakter Rainbow sebagai perempuan yang kuat dan pemberani dapat dilihat dari penggalan dialog:

169. Rainbow: Moekerdji keluarlah engkau, kalau tidak di dalam kegentingan yang semacam ini, sudah tentu saya kasih tahu sama saya punya daddy! Sekarang keluarlah kau, kalau kau tidak mau keluar, saya tikam saja punya badan sendiri, 
bukannya kau yang saya bunuh, melainkan saya sendiri enyalah kau dari sini!

Dari cuplikan dialog di atas, terlihat bahwa tokoh Rainbow tidak takut dan berani menantang orang yang ingin melakukan kejahatan terhadapnya. Adegan tersebut menggambarkan bahwa meskipun sering dianggap lemah, tetapi perempuan tidak bisa dianggap rendah.

Selain hadir sebagai tokoh perempuan yang kuat dan pemberani, Rainbow juga hadir sebagai tokoh perdamaian. Rainbow adalah tokoh kunci yang membuat Kerajaan Sungai Lemau dan Pemerintahan Inggris berdamai. Melalui tokoh Rainbow, Soekarno mempertegas eksistensi perempuan di tengah-tengah kehidupan masyarakat. Drama RPKB adalah media kritik Soekarno terhadap sistem sosial yang ada di Bengkulu sekaligus memberikan eduksi tentang peran dan posisi perempuan di tengah masyarakat.

\section{Mewaspadai Pengkhianat}

Soekarno beranggapan, musuh yang menghambat jalan kemerdekaan Indonesia tidak hanya bangsa kolonial, tetapi juga para anak bangsa yang memutuskan menggadaikan harga diri bangsa untuk menjadi pengkhianat. Salah satu faktor yang membuat para pengkhianat lahir adalah janji kemapanan yang ditawarkan oleh penjajah. Salah satu ciri dari pengkhianat bangsa adalah memanfaatkan situasi untuk keuntungannya pribadi.

Di dalam drama RPKB, Soekarno menghadirkan tokoh pengkhianat yang bernama R. Moekerdji. Orang hidustan yang berasal dari Madras ini bekerja sebagai kepala tukang pembangunan di Benteng Marlborough. Di tengah perang antara Kerajaan Sungai Lemau dan Pemerintah Inggris, R. Moekerdji memanfaatkan situasi untuk memenuhi nafsunya kepada Rainbow. Selengkapnya dapat dilihat dari penggalan dialog 164168:

Captain lantas berangkat dan Com pun berangkat juga, sebab perang telah mulai. Rainbow tinggal sendirian. R. Moekerdji masuk. Rainbow sangat terkejut. (di luar terdengarlah bunyinya senapan dan meriam).

164. R. Moekerdji: Lady, adalah tuan Com di sini?

165. Rainbow: Tidak ada, daddy ada di luar, sebab mengatur berperang, keluarlah engkau Moekerdji!

166. R. Moekerdji: Lady! Saya menunggu di sini saja, sebab saya sangat perlu dengan Com, tidak apa lady, jangan takut apa-apa! Tetapi lady, saya lihat di mata lady, bahasa lady akan mendapat bahaya, marilah tangan lady itu saya lihat.

167. Rainbow: Tidak! Saya tidak akan mengasih tangan saya kepada kau. Keluarlah kau Moekerdji.

168. R. Moekerdji: Lady, jangan takut! Saya seorang tukang tenung, sebab saya punya bapak adalah seorang ahli nujum, kemarikan kau punya tangan itu.

Dari penggalan dialog di atas, tergambar bahwa R. Moekerdji memanfaatkan situasi perang untuk memenuhi keinginan pribadinya. Akibat dari pengkhianatan tersebut, Rainbow, Dewi Pelaka dan Kimas Moeda akhirnya tewas. Melalui tokoh R. Moekardji, Soekarno ingin memberikan edukasi kepada rakyat Indonesia, bahwa pengkhianat atau musuh di dalam selimut lebih berbahaya dibandingkan para 
penjajah.

Melalui drama RPKB, Soekarno juga menghimbau kepada para pejuang kemerdekaan Indonesia untuk lebih mewaspadai kehadiran pengkhianat di sekitar mereka. Mulai dari rakyat, atau bangsawan hingga para aristokrat bahkan orang asing sekalipun, jika berpihak kepada Belanda maka termasuk ke dalam golongan pengkhianat bangsa. Soekarno mempertegas bahwa tidak ada kata damai untuk para pengkhianat. Mereka harus dibasmi agar kemerdekaan dapat diraih.

\section{Kekuatan Tekad}

Merdeka adalah manifestasi dari tekad Indonesia. Untuk mencapainya, dibutuhkan tekad yang kuat dan tidak mudah luntur. Sebagai pemimpin perjuangan, Soekarno selalu menyatukan dan memperkuat tekad rakyat Indonesia untuk mencapai kemerdekaan melalui orasi-orasinya. Memiliki tekad yang kuat adalah landasan untuk sebuah pergerakan yang besar.

Namun sejak tahun 1934, Soekarno mendapatkan larangan keras untuk berpidato lagi oleh Pemerintah Belanda. Sejak saat itu, Soekarno mengganti media orasinya melalui berbagai bidang, salah satunya teater. Drama RPKB adalah salah satu contoh usaha Soekarno untuk menyatukan tekad rakyat Indonesia. Melalui drama RPKB, Soekarno menegaskan pentingnya tekad yang kuat dalam sebuah perjuangan. Soekarno menyampaikan visinya melalui tokoh Kimas Moeda yang bertekad menyelamatkan Rainbow di tengah situasi perang. Tekad tersebut tergambar dari sumpah Kimas Moeda kepada Senopati Moeda, selengkapnya dapat dilihat dari penggalan dialog 148:

148. Kimas Moeda: Dengar sumpah adinda, adinda bersumpah, disaksi dengan bumi dan angkasa, disaksi dengan lautan Hindia, disaksi dengan pulau Perca Selatan, sekiranya jadi peperangan ini adinda tetap memperlindungi Rainbow, walaupun serangan darimana juga pun. Kalau dalam pertempuran ini adinda tewas jiwanya adinda kakandalah jadi melindungi dan menjaga Rainbow.

Dari penggalan dialog di atas, tergambar bahwa Kimas Moeda rela mengorbankan nyawanya demi menyelamatkan orang yang ia cintai. Tekad seperti itulah yang diinginkan Soekarno agar dimiliki rakyat Indonesia, tekad untuk berkorban jiwa dan raga demi bangsa yang dicintai. Kekuatan tekad dipertegas Soekarno melalui tokoh Senopati Moeda yang bersumpah untuk tidak akan kembali ke Balai Boentar sebelum dendamnya terbalaskan. Selengkapnya dapat dilihat dari penggalan dialog 234:

234. Senopati Moeda: R. Moekerdji, Moekerdji, engkau seorang lelaki yang gagah berani, tetapi kelaki-lakianmu itu adalah sebagai seorang pengecut, seorang berhati perempuan. Kau mengambil jiwanya Kimas Moeda dari belakang, kau mengambil jiwanya seorang perempuan yang bersifat lemah. Moekerdji, kalau sekiranya betul kau lelaki yang berani, tunggulah saya yang akan meuntut belanya. Walaupun kau bersembunyi di ujung bumi sekalipun, saya tentu akan mendapatkan kau. Moekerdji, selagi ajal dikandung badan, selagi darah mengalir di tubuhnya Senopati, selagi 
jantungnya berdebar-debar dan memuai Senopati akan tetap membunuh ....

Dari cuplikan dialog di atas, kekuatan tekad tokoh Senopati Moeda terlihat dari sumpahnya untuk membalas dendam. Tekad Senopati Moeda yang pantang menyerah sebelum sumpahnya terpenuhi adalah salah satu tekad yang harus dimiliki rakyat Indonesia. Perjuangan tidak boleh terhenti dan rakyat Indonesia tidak boleh menyerah sampai dapat meraih kemerdekaan.

Melalui tokoh Kimas Moeda dan Senopati Moeda, Soekarno menggambarkan bahwa sebuah perjuangan haruslah memiliki tekad yang kuat. Kemerdekaan akan tercapai jika semua rakyat Indonesia memiliki tekad yang sama. Melalui drama RPKB, Soekarno memberikan edukasi kepada raykat Indonesia untuk percaya pada kekuatan tekad sebagai jalan menuju kemerdekaan.

\section{Visi Dramatik \\ Kontekstual}

\section{Memenuhi Kebutuhan Estetika}

Darah seni yang mengalir di tubuh Soekarno menjadikannya sebagai insan seni yang memiliki potensi estetik. Segala macam kegiatan yang dilakukannya, tidak terlepas dari nilainilai estetis. Kecenderungan inilah yang mendekatkan kehidupan Soekarno dengan proses-proses kreatif kesenian. Begitu juga ketika ia diasingkan ke Bengkulu, kegiatan yang difokuskan oleh Soekarno adalah membentuk dan mengelola kelompok kesenian, yaitu Monte Carlo.

Proses kreatif yang dilakukan oleh Soekarno bersama kelompok Monte Carlo adalah salah satu cara untuk memenuhi kebutuhan estetikanya sendiri. Tanpa seni, hidup Soekarno tidak memiliki gairah dan semangat. Pengalaman kelam di dalam penjara Suka Miskin menjadi salah satu pengalaman traumatik yang mengganggu psikis Soekarno. Tanpa menceburkan diri ke dalam dunia seni, Soekarno seolah-olah masih saja merasa terkurung di dalam penjara.

Kebebasan Soekarno berekspresi di dalam karya seni membuatnya sadar bahwa ia telah bebas dari segala macam penjara. Kesadaran inilah yang kemudian membuat Soekarno kembali bangkit dan melanjutkan visi besarnya, yaitu memerdekakan Indonesia. Proses berkesenian adalah proses pemulihan bagi Soekarno yang sempat terpuruk ketika dipenjara di Suka Miskin dan diasingkan ke Ende. Sehingga memenuhi kebutuhan estetika bagi Soekarno adalah cara untuk menggairahi dan menyemangati hidupnya sendiri.

\section{Menjalin Relasi Sosial}

Saat diasingkan, Soekarno mendapatkan pengawasan yang ketat dari polisi kolonial. Setiap warga yang ingin menjalin komunikasi dengan Soekarno mendapatkan peringatan dan teguran. Hal ini membuat masyarakat takut untuk mengakrabkan diri kepada Soekarno. Situasi ini membuat Soekarno sangat menderita, kesepian yang dirasakannya membuat ia merasa seolah-olah masih terkurung di dalam penjara Suka Miskin. Perasaan itu ia rasakan saat diasingkan ke Ende dan berlanjut pada saat diasingkan ke Bengkulu.

Namun saat diasingkan ke Bengkulu, bukan hanya karena takut oleh polisi kolonial Belanda, tetapi masyarakat Bengkulu menjauhi Soekarno karena pikirannya yang dianggap terlalu dinamis 
tentang agama. Masyarakat Bengkulu saat itu tidak menerima usulan Soekarno untuk melepaskan tabir yang menghalangi kaum perempuan. Ketegangan sosial itulah yang menjadi faktor utama yang membuat rasa kesepian Soekarno di Bengkulu menjadi lebih besar dibandingkan saat ia diasingkan di Ende.

Salah satu cara Soekarno untuk mengakrabkan diri kepada masyarakat adalah dengan merancang pertunjukan teater. Teater bagi Soekarno adalah sarana untuk menghibur masyarakat, karena pada saat itu sarana hiburan bagi masyarakat masih relatif minim. Soekarno berharap dengan terhiburnya masyarakat Bengkulu, maka kecurigaan dan rasa benci mereka kepada Soekarno menjadi menurun. Cerita yang Soekarno angkat pada awal-awal proses kreatifnya adalah sejarah tentang Bengkulu dengan judul Rainbow: Poetri Kentjana Boelan. Cerita ini memiliki latar persitiwa, latar budaya dan latar sejarah yang sangat akrab dengan masyarakat Bengkulu. Cara ini dilakukan Soekarno untuk mengakrabkan diri dan mendapatkan kembali simpati dari masyarakat Bengkulu.

\section{Membangun Basis Massa}

Perjuangan

merebut

kemerdekaan mengharuskan Soekarno untuk mengumpulkan dan membentuk kekuatan. Bersama Partai Nasional Indonesia (PNI), Soekarno telah membentuk basis masa yang besar. Enam organisasi besar berhasil dihimpun untuk bekerja sama dengan PNI, yaitu Boedi Oetomo, Pasundan, Sumatranen Bond, Kaum Betawi, Indonesische Studieclub, dan Algemene Studie Club. Ketujuh organisasi tersebut kemudian membentuk sebuah wadah yang dinamakan Permufakatan Perhimpunan-perhimpunan Politik Kebangsaan Indonesia (PPPKI).

$\begin{array}{lcr}\text { Namun } & \text { ketika } & \text { Soekarno } \\ \text { diasingkan, } & \text { pemerintah } & \text { Belanda } \\ \text { membatasi } & \text { segala aktivitas } & \text { sosial }\end{array}$
Soekarno. Orang-orang yang bertemu dengan Soekarno akan diintrogasi oleh Belanda. Cara ini efektif untuk membuat rakyat Indonesia menjauhi Soekarno. Selain itu, lokasi pengasingan yang dipilih Belanda adalah daerah yang non-politis. Sehingga Soekarno kehilangan kekuatan secara politik untuk kembali merancang pergerakan nasional.

Cara yang dipilih Soekarno untuk kembali membentuk pasukannya adalah melalui seni teater. Kerja teater adalah kerja kolektif, sehingga membutuhkan banyak pendukung. Soekarno bisa memanfaatkan teater sebagai cara untuk membentuk basis massanya kembali. Selain itu, aktivitas pengumpulan massa yang dilakukan Soekarno tidak dianggap sebagai aktivitas yang berbahaya bagi pemerintah Belanda, karena menurut Belanda Soekarno sudah tidak tertarik kepada politik dan lebih memfokuskan diri kepada seni pertunjukan.

\section{Membentuk Ruang Dialogis}

Berdiskusi dan bertukar ide bagi Soekarno adalah cara efektif untuk membentuk sebuah hubungan yang produktif. Sejak masih di Surabaya, Soekarno muda sudah tertarik dengan diskusi. Bersama dengan para petinggi Sarekat Islam, Soekarno banyak membahas berbagai persoalan terutama tentang kemerdekaan Indonesia. Ketika Soekarno berkuliah di Bandung, ia juga membentuk ruang diskusi yang diberi nama Algemeene Studie Club. Bersama dengan kelompok diskusinya, Soekarno mulai menyusun konsep dan perencanaan 
tentang pergerakan revolusinya.

Tidak hanya membuka diskusi bersama kaum terpelajar, Soekarno juga mengajak rakyat yang tidak berpendidikan untuk ikut serta dalam diskusinya. Melalui ruang-ruang diskusinya, Soekarno memberikan kuliah-kuliah tentang politik agar rakyat Indonesia sadar akan bahaya kolonialisme dan imperialisme serta pentingnya sebuah kemerdekaan. Bagi Soekarno, semakin banyak rakyat yang sadar akan keterjajahannya maka semakin besar pula peluang untuk Indonesia merdeka. Maka dari itu, Soekarno gencar untuk mengajak rakyat Indonesia untuk belajar dan berdiskusi bersamanya.

Kegiatan

diskusi

yang

diselenggarakan Soekarno dianggap sebagai ancaman oleh pemerintah kolonial. Hal inilah yang menjadi salah satu faktor yang membuat Soekarno diasingkan. Ketika Masa pengasingan, Soekarno dilarang untuk membentuk ruang dialogis lagi, terutama ruang diskusi politik. Segala macam hubungan sosial Soekarno dibatasi dan mendapatkan pengawasan yang ketat. Saat kehadiran ruang diskusi dalam bentuk apapun telah dilarang, Seokarno kembali mencari cara agar dapat menjalin komunikasi dengan rakyat Indonesia. Salah satu caranya adalah melibatkan rakyat untuk memproduksi pertunjukan toneel.

Setelah latihan atau sebelum latihan, Soekarno menyempatkan diri untuk berdiskusi dengan tim pendukungnya. Diskusi tersebut tidak mendapatkan pengawasan dari polisi kolonial, karena hanya dianggap sebagai proses berkesenian yang tidak memiliki tendensi politik. Dengan demikian, terciptalah kembali ruang dialogis yang lebih privat dan terselubung.

\section{Mempersiapkan Kader Cendekiawan}

Soekarno berpendapat bahwa kemerdekaan Indonesia haruslah diperjuangkan oleh rakyatnya sendiri, karena penguasa kolonial tidak akan memerdekaan suatu daerah jajahannya. Terlebih lagi, Indonesia adalah daerah jajahan yang menguntungkan secara ekonomis bagi bangsa kolonial. Maka dari itu, setiap rakyat harus memiliki kesadaran untuk bersatu dan berjuang merebut kemerdekaan bangsanya sendiri.

Sayangnya,

Indonesia prakemerdekaan didominasi oleh rakyat yang minim pendidikan dan bahkan buta huruf. Kaum yang non-terpelajar ini tidak mengerti tentang konsep kemerdekaan dan bahkan mereka juga tidak sadar akan keterjajahannya. Inilah salah satu faktor yang membuat Indonesia tidak mampu melepaskan diri dari kekuasaan kolonial Belanda. Dibutuhkan kader-kader cendekiawan yang mampu mendidik dan mengorganisir rakyat Indonesia agar memiliki satu visi, satu tekad dan satu tujuan yang sama, yaitu kemerdekaan Indonesia.

Kelompok Monte Carlo adalah media Soekarno untuk mendidik caloncalon cendekiawan dari Bengkulu. Proses kreatif yang Soekarno lakukan bersama anggota kelompok Monte Carlo dimanfaatkan Soekarno untuk bertukar pikiran serta menjalankan visinya yaitu mempersiapkan kader cendekiawan tanpa disadari oleh pemerintah kolonial.

Salah satu kader cendekiawan dari Bengkulu hasil didikan Soekarno adalah A.M. Hanafi. A.M. pada nama Hanafi merupakan singkatan dari Anak Marhaen 
(Setiyanto, 2006: 42). Gelar tersebut digunakan oleh Hanafi setelah belajar banyak tentang paham marhaenisme dari Soekarno. Putra asli Bengkulu ini disiapkan sebagai pemimpin pergerakan dari basis massa yang telah dibentuk oleh Soekarno di Bengkulu. Saat Soekarno pergi meninggalkan Bengkulu, A.M. Hanafi adalah penghubung antara Soekarno dan rakyat Bengkulu, sehingga komunikasi tentang rencana pergerakan nasional dapat tersampaikan dengan baik ke rakyat Bengkulu.

Tidak hanya berperan saat prakemerdekaan, A.M. Hanafi tetap mengabdikan dirinya untuk Indonesia pascakemerdekaan. Setelah Indonesia merdeka, A.M. Hanafi ditugaskan Soekarno sebagai Menteri Urusan Tenaga Rakyat dan kemudian dipindahtugaskan sebagai duta besar Indonesia untuk Republik Kuba di Havana. A.M. Hanafi adalah bukti dari keberhasilan Soekarno dalam mengkader para calon cendekiawan prakemerdekaan Indonesia di Bengkulu.

\section{KESIMPULAN}

Visi dramatik adalah gambaran dunia ideal yang dicita-citakan oleh pengarang drama. Kehadiran visi dramatik menjadi pedoman yang melandasi dan menginspirasi pengarang dalam menulis drama. Formulasi visi dramatik tersusun berdasarkan refleksi dari pengarang drama atas keadaan sosial dan kondisi zaman yang dialaminya. Visi dramatik berada pada ranah subjektif, karena dipengaruhi oleh aspek emosional dan intelektual.

Soekarno adalah pejuang kemerdekaan Indonesia yang memiliki potensi estetik di dalam dirinya, sehingga segala aktivitasnya tidak terlepas dari nilai-nilai estetika. Seni bagi Soekarno adalah media propaganda yang dimanfaatkannya untuk menyampaikan visi perjuangannya kepada rakyat Indonesia. Karir kesenimanan Soekarno dimulai ketika ia diasingkan ke Ende (1934-1938), kemudian berlanjut saat diasingkan ke Bengkulu (1938-1942). Proses kreatifnya di Bengkulu dilakukan bersama dengan kelompok toneel Monte Carlo.

Visi dramatik Soekarno yang terkandung di dalam drama RPKB secara tekstual adalah memberikan edukasi dan menumbuhkan kesadaran kepada rakyat Indonesia, khususnya rakyat Bengkulu. Sedangkan visi dramatik Soekarno secara kontekstual adalah menjalin komunikasi dan merancang perjuangan bersama rakyat. Berdasarkan penelusuran visi dramatik Soekarno dalam drama RPKB secara tekstual dan kontekstual, tergambar bahwa Soekarno memiliki citacita tentang kemerdekaan Indonesia yang diraih oleh tangan rakyatnya sendiri.

\section{DAFTAR PUSTAKA}

Adams, Cindy. 2018. Bung Karno Penyambung Lidah Rakyat. Jakarta: Yayasan Bung Karno dan Penerbit Media Pressindo. Edisi Revisi.

Casado, Elvira Jensen, Review The Dramatic Vision of August Wilson by Sandra G. Shannon, Atlantis, No. 1/2, Vol. 18, Junio Diciembre 1996.

Giebels, Lambert. 2001. Soekarno Biografi 1901-1950. Jakarta: Gramedia Widiasarana Indonesia.

Khare R.R. 1998. Shakespeare, Eugene O'Neill, T.S. Eliot and the Greek Tragedy. New Delhi India: Mittal Publications.

Leach, Robert, 2008. Theatre Studies: 
The Basics. New York: Routledge.

Sahid, Nur. 1995. Pengaruh Modernisasi terhadap Kehidupan beberapa Senis Pertunjukan Jawa Tradisional, Yogyakarta: Basis.

Setiyanto, Agus. 2006. Bung Karno Maestro Monte Carlo. Yogyakarta: Penerbit Ombak.

Soekarno, 1963. Di Bawah Bendera Revolusi, Jilid 1 Cetakan 2, Jakarta: Panitia Penerbit.

Strom, William. 1998. After Dionysus: $A$ Theory of the Tragic. United States of America: Cornell University Press.

Tim, Eitel Friedrich dan Kenneth Mendoza. 1993. The Poetics of Reading. Columbia: Camden House.

Winet, Evan Darwin. 2010. Indonesian Postcolonial Theatre: Spectral Genealogies and Absent Faces. United Kingdom: Palgrave Macmillan. 